\title{
Glutathione, Cell Proliferation, and 1,3-bis-(2-chloroethyl)-1-Nitrosourea in K562 Leukemia
}

\author{
Henri Frischer, ${ }^{\star *}$ Eugenia J. Kennedy, ${ }^{\star}$ Rajababu Chigurupati, ${ }^{\star}$ and Muthumalayan Sivarajan ${ }^{\star}$ \\ ${ }^{*}$ Department of Medicine (Hematology) and ${ }^{\ddagger}$ Pharmacology (Genetics), Rush-Presbyterian-St-Luke's Medical Center, \\ Rush University, Chicago, Illinois 60612
}

\begin{abstract}
We have pursued our findings of glutathione reductase (GSSGR) deficiency and disturbed glutathione in cancer patients treated with 1,3-bis-(2-chloroethyl)-1-nitrosourea (BCNU), by investigating how thiol metabolism, cell proliferation, and the nitrosourea interact in human $\mathrm{K562}$ leukemia. Fasting cells arrested in G greatly increased their reduced glutathione (GSH) in response to growth factors. The rise in thiol began after several hours, peaked before DNA synthesis, and resulted from increased production. BCNU inactivated GSSG-R rapidly, and later retarded, doubled, and greatly prolonged GSH formation before stopping DNA synthesis. Pretreatment unlike post treatment with buthionine-S-R-sulfoximine (BSO) diminished BCNU's ability to block GSSG-R. Enzyme inhibition decreased with falling cellular GSH. In the leukemia system as in vivo, sequential BCNU-induced thiol alterations heralded delayed antiproliferative effects. Drug timing markedly affected both thiol and DNA syntheses. By destroying GSSG-R and delaying the upregulation of thiol synthesis while escalating GSH utilization and requirements, the nitrosourea created a striking and previously unrecognized window of vulnerability for GSH-dependent processes. During this period, altered GSH metabolism could contribute indirectly to BCNU's pleiotropic effects by interfering with DNA alkylation repair, glucose decarboxylation, deoxyribose formation, and possibly by influencing other aspects of proliferation. Acquired GSSG-R deficiency was also an early and sensitive marker for prodrug breakdown and activation. (J. Clin. Invest. 1993. 92:27612767.) Key words: glutathione-reductase • proliferation • carmustine $\bullet$ sulfoximine $\bullet$ K562-leukemia
\end{abstract}

\section{Introduction}

Investigations of the pharmacogenetics of oxidative hemolysis in various populations uncovered eventually that, in patients with hematological malignancies, therapeutic doses of antitumor 1,3-bis-(2-chloroethyl)-1-nitrosourea (BCNU) interrupted recycling of glutathione disulfide (GSSG) into GSH by inactivating glutathione reductase (GSSG-R) rapidly and

Address correspondence to Henri Frischer, MD, PhD, Department of Medicine (Hematology) and Pharmacology (Blood Genetics and Pharmacogenetics), Rush-Presbyterian-St-Luke's Medical Center, 1753 W. Congress Parkway, Chicago, IL 60612. 1993.

Received for publication 9 March 1993 and in revised form 9 July

J. Clin. Invest.

(c) The American Society for Clinical Investigation, Inc.

0021-9738/93/12/2761/07 \$2.00

Volume 92, December 1993, 2761-2767 irreversibly throughout the body (1-4). ${ }^{1}$ The acute GSSG-R deficiency led to marked erythrocyte GSH instability in response to oxidants, while cellular thiol content remained unaffected or decreased slightly. We were surprised to observe that later, in bloods obtained 10, 14, and 16 wk after the last (sixth) weekly course of BCNU, the levels of erythrocyte GSH were much higher than they had been in the basal pre-chemotherapy samples (4). In subsequent years, the inhibition of GSSG-R by BCNU became widely used to probe the impact of altered GSH oxidoreduction in many biological contexts, new pleiotropic drug effects were uncovered (5-11), GSSG-R deficiency was incriminated etiologically in delayed pulmonary toxicity (1215), the "rebound" increase of GSH after exposure to the drug was confirmed in several systems $(13,14,16)$, and impressive progress was made in clarifying the role of $\mathrm{O}^{6}$-alkylated guanine adduct formation and repair in the pharmacology of nitrosoureas (17-25). Nevertheless, several aspects of the biological response to these agents remain poorly understood, including the potential relationship between antitumor effects and thiol alterations. For these reasons and because GSH supports many cell functions including proliferation, detoxification, enzyme protection, and drug metabolism (7-11, 26-30), we have extended our earlier work concerning the GSSG-R deficiency and thiol disturbances that develop after chemotherapy with BCNU.

To clarify underlying mechanisms and potential signifcance, it seemed desirable to investigate the relationship between thiol metabolism, cell proliferation, and BCNU in a human malignant line. We chose K562 leukemia cells because they synthesize and recycle GSH efficiently, they are sensitive to $\mathrm{BCNU}$, and because their growth in liquid cultures can be arrested, reinstated, and coordinated without drugs by manipulating the supply of fresh serum and nutrients (31-33). GSH, consumed as an adduct or in oxidoreduction, can be replenished by de novo synthesis and by recycling GSSG $(26,27)$. De novo synthesis is regulated primarily by the supply of aminoacid substrates for the rate-limiting GSH-cysteine synthase, and by feedback inhibition of this enzyme by GSH, the end product of GSH synthase $(26,27)$. Recycling of GSSG on the other hand depends exclusively on GSSG-R, a ubiquitous NADPH-dependent enzyme, that restores GSH effectively and with great flexibility by responding to and regulating the flux of glucose through the hexose monophosphate shunt (HMS) (8, 11). We have therefore defined quantitative changes in GSH and their temporal association with cell growth by measuring thiol levels, GSH synthesis, GSSG recycling, hexose shunt de-

1. Abbreviations used in this paper: $\mathrm{BCNU}, 1,3$-bis-(2-chloroethyl)-1nitrosourea; BSO, buthionine sulfoximine; G6PD, glucose-6-phosphate dehydrogenase; GSSG, glutathione disulfide; GSSG-R, glutathione reductase; HMS, hexose monophosphate shunt; 6PGD, 6-phosphogluconic dehydrogenase. 
hydrogenase activities, and DNA synthesis before and after the arrested leukemic cells were stimulated to proliferate. The impact of BCNU on GSSG-R, GSH, and DNA synthesis was measured in cells exposed to the drug at different stages of proliferation. The contributions of synthesis and oxidoreduction in maintaining GSH were analyzed by using buthionine sulfoximine $(\mathrm{BSO})(27,34)$ as well as $\mathrm{BCNU}$.

\section{Methods}

Materials. BCNU was obtained from Bristol Labs (Syracuse, NY). BSO was from Chemalog (South Plainfield, NJ). Scintisol ${ }^{R}$ scintillation cocktail was from United Technologies Packard (Downers Grove, IL). Glutathione, NADPH, GSSG-R, GSSG, $N$-ethyl maleimide (NEM), disodium EDTA, Trizma ${ }^{\mathrm{R}}$, cysteine, 5,5'-dithiobis-(2-nitrobenzoic acid (DTNB), and Folin \& Ciocalteu phenol reagent were from Sigma Chemical Co. (St. Louis, MO).

Cell cultures. The K562 cell line was maintained in RPMI 1640 media supplemented with $10 \%$ heat inactivated fetal calf serum (both from Gibco, Grand Island, NY), antibiotics (penicillin $180 \mathrm{U} / \mathrm{ml}$, streptomycin $0.18 \mathrm{mg} / \mathrm{ml}$; Eli Lilly \& Co., Indianapolis, IN, gentamicin $36 \mu \mathrm{g} / \mathrm{ml}$, Schering-Plough Corp., Kenilworth, NJ, amphotericin B $9 \mathrm{mcg} / \mathrm{ml}$; E. R. Squibb \& Sons, New Brunswick, NJ), hepes buffer $0.02 \mathrm{~mol} /$ liter pH 7.3 (Gibco), and sodium hydroxide $10 \mathrm{~N} 0.5 \mathrm{ml}$ (Fisher Scientific, Fair Lawn, NJ). The cells were maintained at $37^{\circ} \mathrm{C}$ in an humidified atmosphere with $5 \% \mathrm{CO}_{2}$ in a NAPCO 6300 incubator (Precision Scientific Inc., Chicago, IL). The cells were starved for 4 $\mathrm{d}$ before each experiment. After fasting synchronization, the spent medium was decanted from the flasks containing K 562 cells, viability was assessed by trypan blue exclusion, and the cells were counted and resuspended with complete medium to a concentration of $10^{6}$ cells per $\mathrm{ml}$ in 50-ml Falcon flasks (Becton Dickinson, Lincoln Park, NJ).

Drug exposures. For the standard early exposure, the test drug ( usually BCNU at $1.25 \times 10^{-5} \mathrm{M}$ ) or buffered saline control was added to K562 cells that had been deprived of fresh nutrients and serum for the preceding $4 \mathrm{~d}$ and had just been resuspended at $10^{6}$ cells $/ \mathrm{ml}$ in fresh RPMI-serum (at $t_{0}$ ). At this stage the cells were still predominantly in the $\mathrm{G}$ lag phase. For the late exposure, the test drug or buffer was added $17.5 \mathrm{~h}$ after the cells had been refed and incubated at $37^{\circ} \mathrm{C}$ in a humidified $5 \% \mathrm{CO}_{2}$ atmosphere. At this stage the cells were mostly in mid-S $\log$ phase. In both experimental groups, the end point measurements $\left(\left[{ }^{3} \mathrm{H}\right]\right.$ thymidine incorporation into DNA, GSSG-R assays, and thiol levels) were obtained $18 \mathrm{~h}$ after the addition of serum-RPMI. To examine whether the anti-GSSG-R property of BCNU was altered in $\mathrm{K} 562$ cells that had been preexposed to BSO, the 4-d-starved cells were first incubated for $18 \mathrm{~h}$ in fresh complete medium. This was followed by incubation with BSO $\left(10-^{5} \mathrm{M}\right)$ or buffer $(24 \mathrm{~h})$, and then by exposure to various concentrations of $B C N U$ ( $30 \mathrm{~min}$ ). To test how BCNU, BSO, or BCNU preceding BSO affected GSH, the thiol was measured in 4-d-fasted K562 cells that had been resuspended in fresh complete medium, and then incubated for $18 \mathrm{~h}$ with either saline alone, BCNU alone $\left(1.25 \times 10^{-5} \mathrm{M}\right)$, BSO alone $\left(10^{-5} \mathrm{M}\right)$, or BCNU $\left(1.25 \times 10^{-5}\right.$ $\mathrm{M})$ followed by BSO $\left(10^{-5} \mathrm{M}\right)$. The incubations preceding the assays for GSSG-R and for GSH were in humidified $5 \% \mathrm{CO}_{2}$ at $37^{\circ} \mathrm{C}$.

DNA synthesis. DNA synthesis was measured by placing $200-\mu 1$ cell samples into microtiter plates. $\left[{ }^{3} \mathrm{H}\right]$ thymidine $(0.5 \mu \mathrm{Ci} /$ well $)$ was added to the wells, and after a 1-h pulse, the cells were harvested on glass fiber filters. These were thrice washed in deionized water in a microharvestor (PHD ${ }^{R}$ model 200A; Cambridge Technol., Inc., Watertown, MA), air-dried, and counted in Scintisol ${ }^{\mathbf{R}}$ in a scintillation counter (4000 series Tri-Carb ${ }^{R}$; Packard Instrument Company), as previously described ( 31 ).

Enzyme assays and GSH studies. After incubation for the appropriate time, the K562 cells were centrifuged (model TJ-6; Beckman Instrs., Inc., Fullerton, CA) at $1000 \mathrm{~g}$ for $10 \mathrm{~min}$ at $26^{\circ} \mathrm{C}$. The supernatant was separated from the $\mathrm{K} 562$ cells and the cells were reconstituted with $0.5 \mathrm{ml}$ of phosphate buffer $\left(0.1 \mathrm{M} \mathrm{PO}_{4}\right.$ containing $0.005 \mathrm{M}$ of
EDTA, pH 7.4). After the samples were frozen and thawed four times in a methanol/dry ice bath, they were centrifuged $\left(15,000 \mathrm{~g}, 5^{\circ} \mathrm{C}\right)$ for $30 \mathrm{~min}$. The supernatant was used to measure GSSG-R, glucose-6-phosphate dehydrogenase (G6PD), 6-phosphogluconic dehydrogenase (6PGD) activities, GSH and GSSG levels, and GSH synthesis as previously described $(1,2,35)$. GSSG-R, G6PD, and 6PGD activities were expressed in $\mu \mathrm{mol}$ NADP $(\mathrm{H})$ oxidized (reduced) $\mathrm{min}^{-1}$ $\mathrm{mg}^{-1}$ protein at $37^{\circ} \mathrm{C}$. GSH levels were expressed as $\mathrm{mg}$ thiol $\mathrm{g}^{-1}$ protein. GSH synthesis activity was expressed as $\mu \mathrm{mol} \mathrm{GSH}$ produced $\mathrm{g}^{-1}$ protein $\mathrm{h}^{-1}$ at $37^{\circ} \mathrm{C}$. Protein was determined according to Lowry (36).

\section{Results}

Pilot studies concerning the growth characteristics of the K562 leukemia line used in our laboratory (31-33) gave the following information (data not shown). The presence of serum in the fresh growth medium was essential for maximum activation of DNA synthesis. After cells received fresh RPMI-serum $\left(t_{0}\right)$ to replace that which had been supplied $4 \mathrm{~d}$ earlier, the mean lag phase before onset of DNA synthesis was $\sim 10 \mathrm{~h}$. Subsequently, thymidine incorporation reached a maximum centered around $26 \mathrm{~h}$ before decaying rapidly and returning to the very low $t_{0}$ baseline values by $32-38 \mathrm{~h}$ after the addition of RPMI-serum. Viability was preserved from days zero to four, and cell counts, adjusted to $10^{5} \mathrm{cells} / \mathrm{ml}$ at $t_{0}$, remained at baseline for at least $26 \mathrm{~h}$ before doubling and redoubling in samples obtained at 48 and $96 \mathrm{~h}$, respectively.

Fig. 1 shows the activities of GSSG-R studied as a function of time in K562 cells treated with BCNU $\left(1.25 \times 10^{-5} \mathrm{M}\right)$ or buffer. In the cells exposed to the nitrosourea, GSSG-R was rapidly inactivated, and this persisted throughout the experimental period. There was no loss of enzyme activity in the no-drug control cells.

Table I shows that the capacity for GSH synthesis and the activities of the hexose monophosphate dehydrogenases were similar before or after resuspending 4-d-starved K562 cells for $24 \mathrm{~h}$ in fresh growth medium with serum. GSH levels were markedly altered by refeeding the cells (Fig. 2). While unsynchronized, nonfasted K562 cells contained $4.0 \pm 1.6 \mathrm{mg}$ $\mathrm{GSH} \mathrm{g}^{-1}$ protein $(n=12)$, the thiol was less than $0.5 \mathrm{mg} \mathrm{g}^{-1}$ in cells that had not received fresh medium for the previous $4 \mathrm{~d}$.

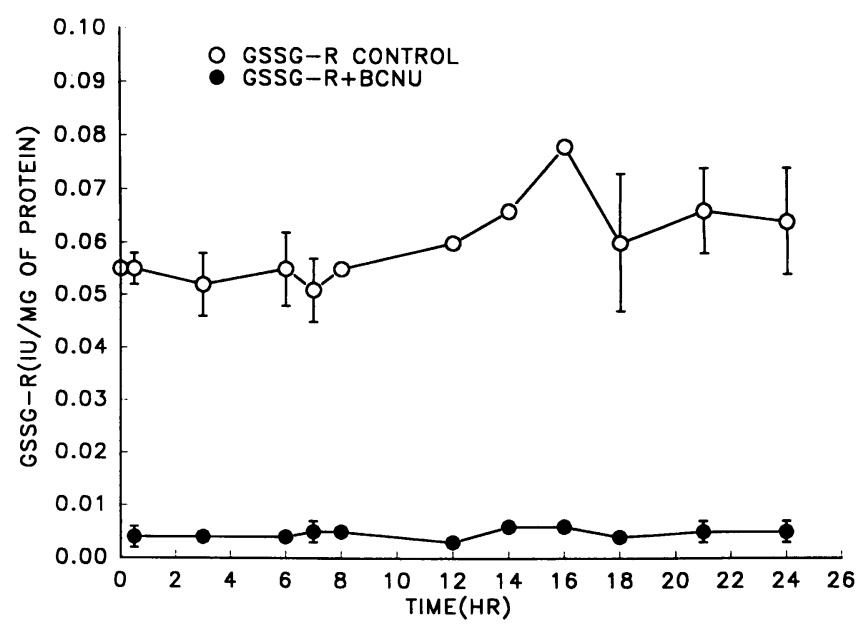

Figure 1. GSSG-R activity as a function of time in K562 cells treated with BCNU $\left(1.25 \times 10^{-5} \mathrm{M}\right)$ or saline (see Methods). Bars represent $\pm 1 \mathrm{SD}, n=7$ 
Table I. GSH Synthesis and Hexose Phosphate Dehydrogenases before and after Refeeding Fasting Synchronized K562 Cells

\begin{tabular}{llc}
\hline & 0 h postfeeding & 24 h postfeeding \\
\hline GSH synthesis & $17.0 \pm 4.1$ & $14.6 \pm 3.3$ \\
G6PD & $0.42 \pm 0.01$ & $0.45 \pm 0.06$ \\
6PGD & $0.25 \pm 0.02$ & $0.24 \pm 0.01$
\end{tabular}

GSH synthesis and hexose phosphate dehydrogenases were assayed in 4-d-starved K 562 cells before and $24 \mathrm{~h}$ after they were resuspended in fresh serum-containing growth medium. GSH synthesis is expressed as $\mu \mathrm{mol} \mathrm{GSH}$ produced $\mathrm{g}^{-1}$ protein $\mathrm{h}^{-1}\left(37^{\circ} \mathrm{C}\right)$. G6PD and 6PGD activities are expressed as $\mu \mathrm{mol}$ NADPH reduced $\mathrm{min}^{-1} \mathrm{mg}^{-1}$ protein $\left(37^{\circ} \mathrm{C}\right)$. The numbers represent the mean \pm 1 standard deviation of three different experiments.

In the synchronized systems without BCNU, the low baseline intracellular GSH level began to increase within $3 \mathrm{~h}$ after addition of fresh medium serum to reach a maximum of $4.2 \mathrm{mg} \mathrm{g}^{-1}$ protein at $6 \mathrm{~h}$. Over the next $6 \mathrm{~h}$ the thiol fell progressively to $3.0 \mathrm{mg} \mathrm{g}^{-1}$ protein or about six times the starting value. This level remained fairly stable for the next $12 \mathrm{~h}$. The baseline level of cellular GSH at $t_{0}$ was inversely proportional to the duration of the previous fasting period, and the thiol increased in starved cells receiving fresh RPMI 1640 medium with or without serum (data not shown).

In the BCNU-treated cells the increase in GSH after refeeding was delayed for $\sim 3 \mathrm{~h}$ when compared with the no-drug control. Thereafter, K562 GSH levels continued to rise. By 12 $\mathrm{h}$ the thiol had reached about twice the maximum values found in the no-drug controls $\left(8.0 \mathrm{mg} \mathrm{g}^{-1}\right.$ protein $)$ and over the next $12 \mathrm{~h}$ the high levels of GSH after BCNU were maintained or increased slightly.

Fig. 3 shows that in K562 cells, BSO, a specific inhibitor of glutathione synthesis, decreased GSH with a $K_{\mathrm{is} 0}$ of $8.5 \times 10^{-7}$ $M$. The fall in GSH was not associated with a rise in GSSG or with changes in the activities of GSSG-R, G6PD, and 6PGD (data not shown). Preexposure to BSO impaired significantly

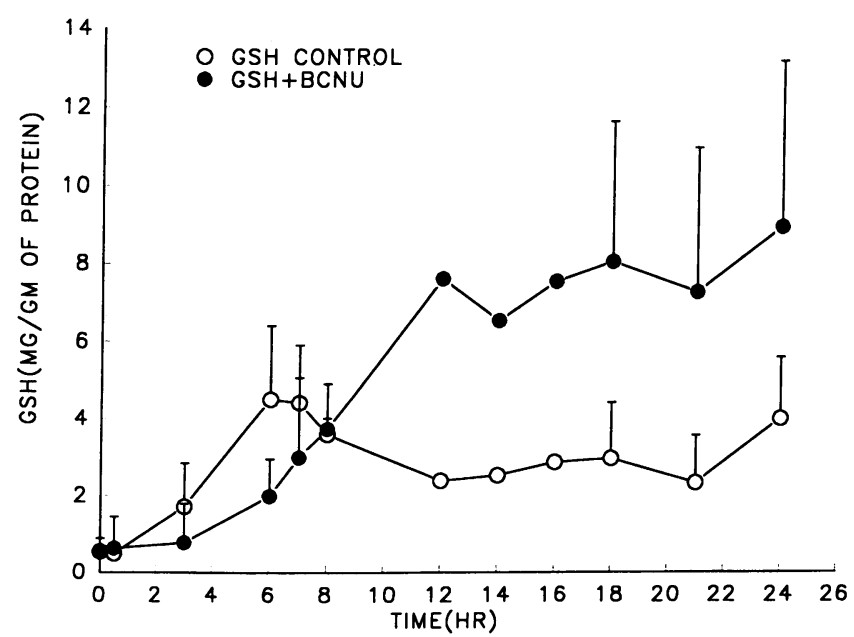

Figure 2. Time course of GSH content in fasting-synchronized K562 cells induced to proliferate without or with $\mathrm{BCNU}\left(1.25 \times 10^{-5} \mathrm{M}\right)$, added immediately after refeeding $\left(t_{0}\right)$ (see Methods) Bars represent $\pm 1 \mathrm{SD}, n=7$.

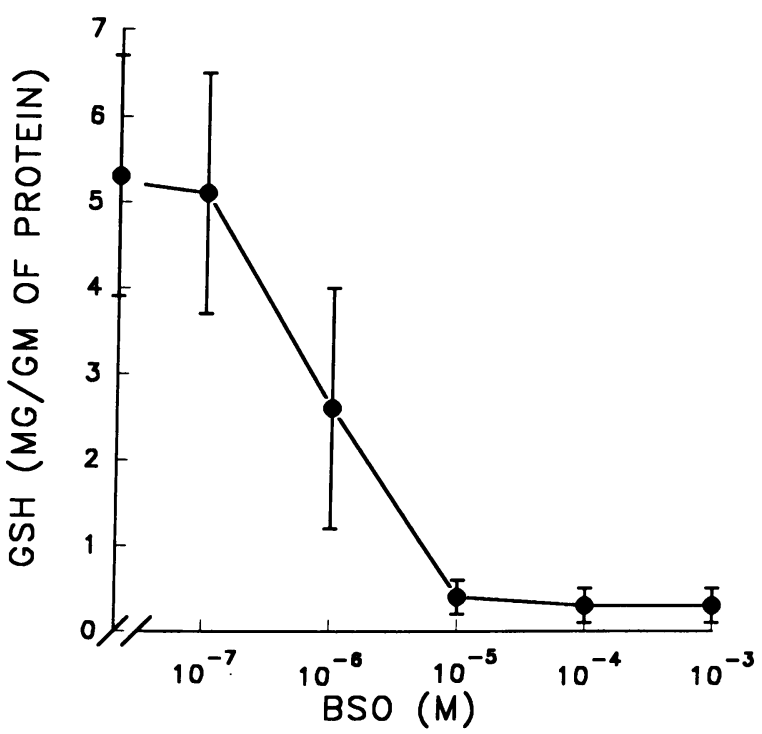

Figure 3. Effect of BSO-induced inhibition of GSH synthesis on GSH content in K562 cells. Bars represent $\pm 1 \mathrm{SD}, n=7$.

the ability of BCNU to inhibit GSSG-R (Fig. 4). Consequently, in the following studies (Fig. 5), treatment with $\mathrm{BCNU}\left(1.25 \times 10^{-5} \mathrm{M}\right)$ preceded incubation with $\mathrm{BSO}\left(10^{-5}\right.$ M). BSO abolished the rise in GSH induced by RPMI-serum in K562 cells that had not (Fig. $5 \mathrm{~A}$ ) or had (Fig. $5 \mathrm{~B}$ ) been treated with the nitrosourea.

Fig. 6 shows the kinetics of DNA synthesis in K562 cells treated without or with BCNU. In these experiments, the cells were pulsed serially with $\left[{ }^{3} \mathrm{H}\right]$ thymidine after resuspension in fresh growth medium with serum. In the no-drug control systems, the serum-containing growth medium stimulated DNA synthesis after a lag period. The duration of the lag period was directly proportional to the length of the previous fasting period (data not shown). In the systems with the standard 4-d fasting period (Fig. 6), and in the no-drug control systems, DNA synthesis began between 6 and $14 \mathrm{~h}$ and continued to

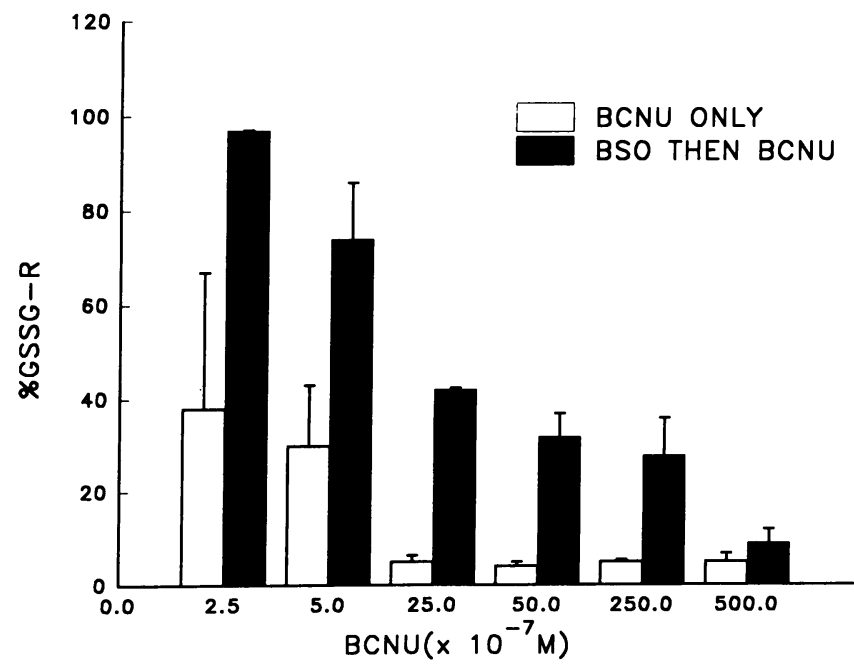

Figure 4. Inhibition of K562 GSH synthesis by BSO interferes with subsequent BCNU inactivation of GSSG-R (see Methods). GSSG-R $100 \%=0.081 \pm 0.009 \mu \mathrm{mol}$ NADPH oxidized $\mathrm{min}^{-1} \mathrm{mg}^{-1}$ protein $\left(37^{\circ} \mathrm{C}\right)$. Bars represent $\pm 1 \mathrm{SD}, n=4$. 

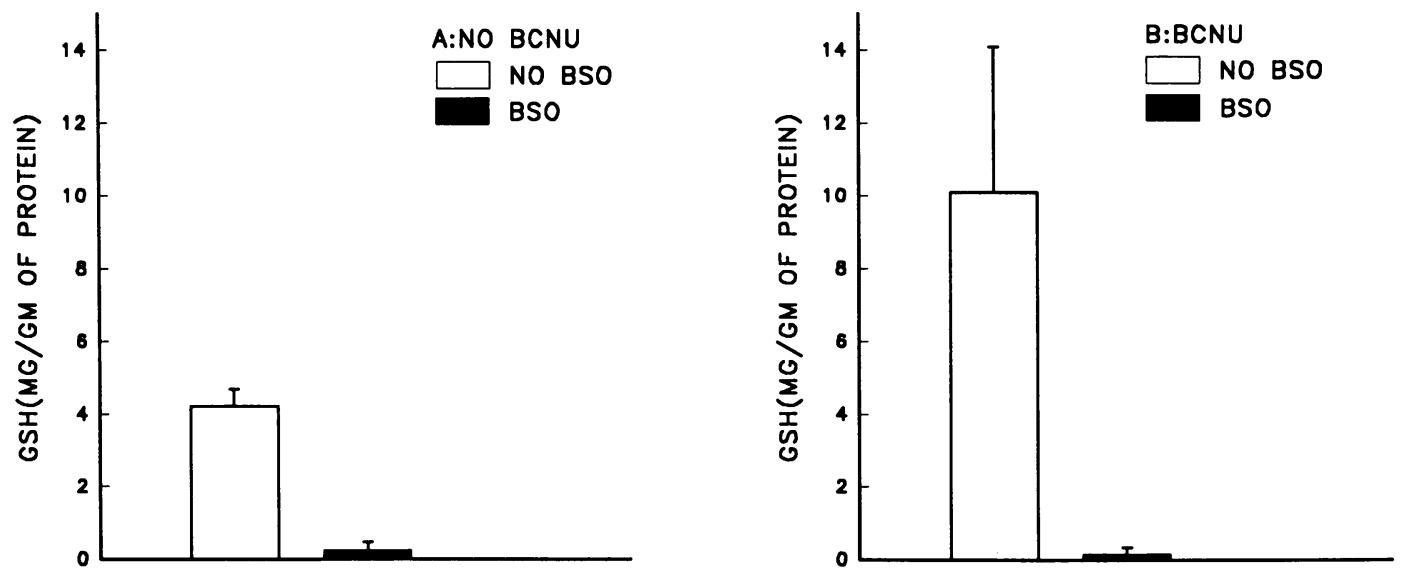

Figure 5. BSO blocks the GSH response to growth stimulation in $\mathrm{K} 562$ cells treated without $(A)$ or with $(B) \mathrm{BCNU}$ (see Methods). Bars represent $\pm 1 \mathrm{SD}, n=3$.

increase until the end of the 24-h experimental period. In the systems with BCNU $\left(1.25 \times 10^{-5} \mathrm{M}\right.$, added at $\left.t_{0}\right)$, the DNA synthesis response after RPMI-serum was completely blocked in all samples, throughout the experimental period.

Next we determined the effect of graded amounts of BCNU on DNA synthesis, GSSG-R activity, and GSH levels (Fig. 7-9) in K562 cells that had been exposed to the drug at two different stages of their growth cycle (see Methods). Fig. 7 shows that BCNU blocked the DNA synthesis response to RPMI-serum in a dose-dependent manner whether the cells were treated with the drug earlier or later. However, the timing of exposure had a marked quantitative impact. BCNU inhibited DNA synthesis with a $K_{\mathrm{i}}$ of approximately $5 \times 10^{-6} \mathrm{M}$ when added immediately after RPMI-serum (early addition in $\mathrm{G} 1$ ). In contrast, when the nitrosourea was added $17.5 \mathrm{~h}$ after the addition of RPMI-serum (late addition in mid-S phase), the $K_{\mathrm{i}}$ increased by an order of magnitude to $\sim 5 \times 10^{-5} \mathrm{M}$. The difference in $K_{\mathrm{i}}$ 's between the systems with early or late drug addition is highly significant $(P<0.005$, Wilcoxon paired rank test).

Fig. 8 shows that BCNU inhibited GSSG-R activity powerfully in a dose-related manner whether the cells had been ex-

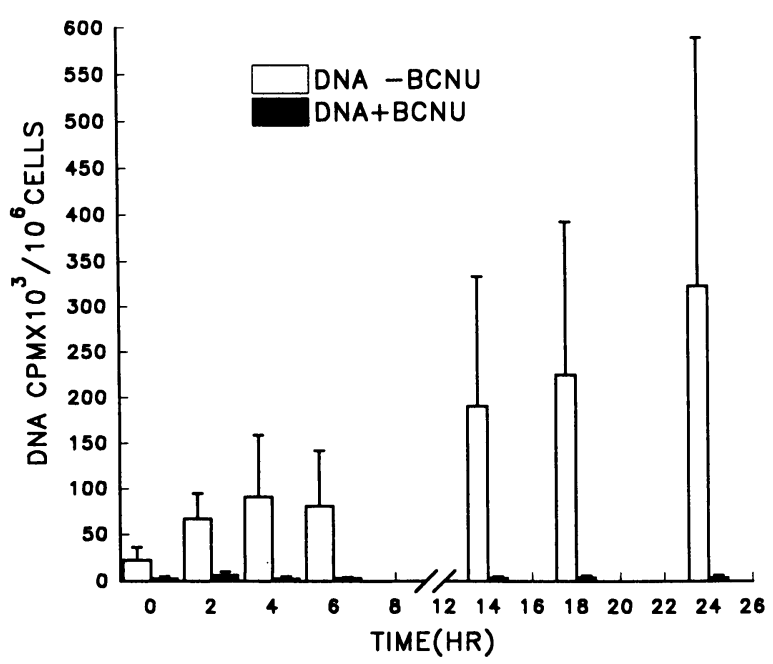

Figure 6. Time course of DNA synthesis in fasting-synchronized $\mathrm{K} 562$ cells induced to proliferate without or with $\mathrm{BCNU}\left(1.25 \times 10^{-5}\right.$ $\mathrm{M}$ ) (see Methods) Bars represent $\pm 1 \mathrm{SD}, n=5$. posed to the drug for $18 \mathrm{~h}$ (Fig. $8 \mathrm{~A}$ ) or for $0.5 \mathrm{~h}$ (Fig. $8 \mathrm{~B}$ ) before the measurements. Enzyme inactivation was more effective when the cells were exposed to the drug at the later time. The mean $K_{\mathrm{i} 50}$ for both types of exposure was $\sim 5 \times 10^{-7} \mathrm{M}$. This value was about 10 and 100 times smaller than the $K_{\mathrm{is0}}$ 's for BCNU-mediated DNA inhibition using early or late drug exposures, respectively.

Fig. 9 shows that the effect of BCNU on K562 GSH levels depended on the time of exposure to the drug. In cells that had been treated with BCNU immediately after they had received fresh RPMI-serum and then sampled $18 \mathrm{~h}$ later (Fig. $9 \mathrm{~A}$ ), intracellular GSH increased progressively, as the drug concentration increased to $1.25 \times 10^{-5} \mathrm{M}$; at higher BCNU concentrations the thiol began to fall. The GSH pattern was very different when the cells were treated with the nitrosourea later, that is,

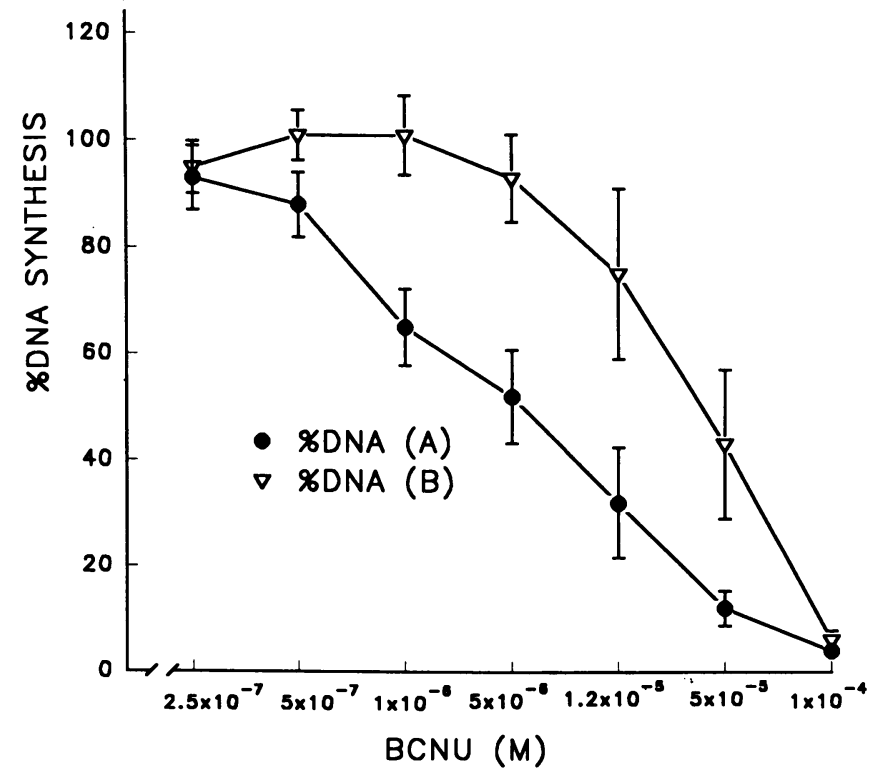

Figure 7. Dose-related inhibition of K562 DNA synthesis by BCNU as a function of drug timing. In $A$, drug exposure took place shortly after the cells were resuspended in fresh medium (early exposure); in $B$, the cells were treated with drug $17.5 \mathrm{~h}$ later (late exposure). See Methods for details. DNA $100 \%(A)=81,915 \pm 19,872 \mathrm{cpm} / 10^{6}$ cells; $100 \%(B)=79,303 \pm 21,499 \mathrm{cpm} / 10^{6}$ cells. Bars represent $\pm 1 \mathrm{SD}, n=8$. 


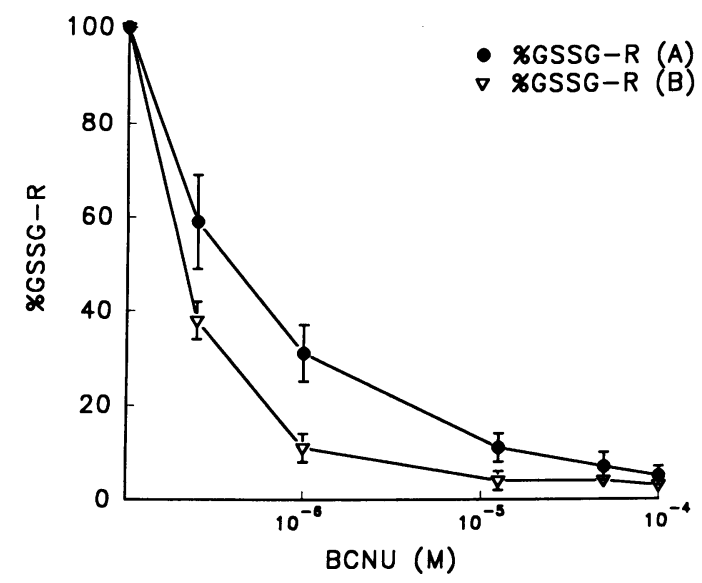

Figure 8. Dose-related inhibition of K562 GSSG-R activity by BCNU as a function of drug timing. In $A$, drug exposure took place shortly after the cells were resuspended in fresh medium (early exposure); in $B$, the cells were treated with drug $17.5 \mathrm{~h}$ later (late exposure). See Methods for details. GSSG-R $100 \%(A)=0.062 \pm 0.007 ; 100 \%(B)$ $=0.061 \pm 0.006$. Activities are expressed as $\mu \mathrm{mol}$ NADP oxidized $\min ^{-1} \mathrm{mg}^{-1}$ protein $\left(37^{\circ} \mathrm{C}\right)$. Bars represent $\pm 1 \mathrm{SD}, n=8$.

$0.5 \mathrm{~h}$ before the sampling time at $18 \mathrm{~h}$. In these systems (Fig. 9 $B)$, GSH never increased but instead began to fall progressively with $\mathrm{BCNU}$ concentrations greater than $10^{-6} \mathrm{M}$.

\section{Discussion}

Human K562 leukemia cells that had been starved for $4 \mathrm{~d}$ incorporated radiolabelled thymidine into DNA poorly. When the spent medium was replaced with fresh nutrient and serum,

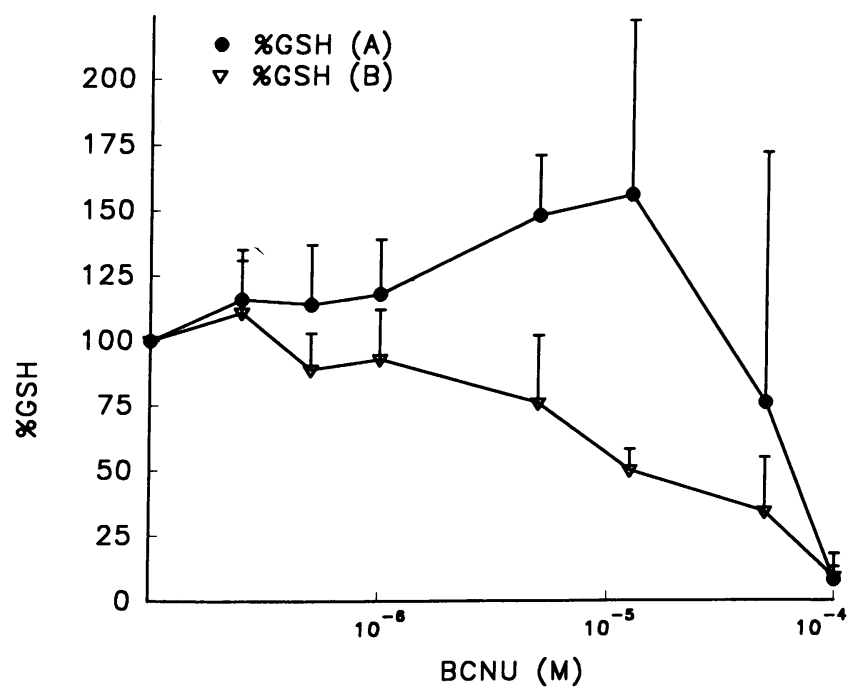

Figure 9. Dose-related alterations of K562 GSH content by BCNU as a function of drug timing. In $A$, drug exposure took place shortly after the cells were resuspended in fresh medium (early exposure); in $B$, the cells were treated with drug $17.5 \mathrm{~h}$ later (late exposure). The ordinate represents GSH and GSSG, in GSH equivalents (see references 26 and 35 and Methods). The no-drug control levels of GSH $(100 \%)$ were measured at $18 \mathrm{~h}$. GSH $100 \%(A)=4.77 \pm 0.34 \mathrm{mg} \mathrm{g}^{-1}$ protein; in $B, 100 \%=5.01 \pm 0.10 \mathrm{mg} \mathrm{g}^{-1}$ protein. Bars represent $\pm 1 \mathrm{SD}, n=8$.
DNA synthesis began after a time lag greater than $6 \mathrm{~h}$. The delayed onset of proliferation in response to growth factors characterizes the fasting method for achieving synchronization and represents the time needed for the bulk of the cell population to cross the boundary between $G$ and $S$ phases (37). As expected, BCNU blocked K562 DNA synthesis in a dose-dependent manner, completely and irreversibly. Unexpectedly, however, we found that the efficacy of BCNU in suppressing K562 DNA synthesis depended on the timing of exposure to the drug. The dose required to block DNA synthesis in cells treated shortly after receiving fresh RPMI-serum, when they were still in the lag phase, was 10 -fold smaller than that needed to produce an equivalent effect if the cells were treated $17 \mathrm{~h}$ later, when they were in log phase. The impact of BCNU was therefore characteristically time dependent, as in patients receiving chemotherapy $(12,15,38,39)$.

The in vitro system also replicated several other features observed in patients treated with BCNU. Such persons became severely GSSG-R deficient long before the antiproliferative and cytotoxic drug effects could be detected. Similarly, in vitro, BCNU inactivated GSSG-R within minutes while many hours were needed to suppress K562 DNA synthesis. Moreover, the leukemic cell enzyme was completely and irreversibly inhibited by less than $5 \times 10^{-6} \mathrm{M}$ drug, a concentration that corresponds approximately to the mean serum blood level found within the first $90 \mathrm{~min}$ of a therapeutic dose of BCNU in humans (75-100 $\left.\mathrm{mg} \mathrm{M}^{-2}\right)(38,39)$.

Leukemia cells that had been starved for $4 \mathrm{~d}$ contained very little GSH. The depressed thiol level could not be attributed to impaired enzymatic recycling of GSSG because the activities of GSSG-R and its supporting HMS dehydrogenases were preserved. GSH synthetases were also intact when assayed in vitro in the presence of optimal substrates and ATP. It was therefore plausible that GSH fell in fasting cells because substrate depletion limited production. This inference was strengthened by finding that the low poststarvation thiol could be raised by providing the cells with fresh growth medium, even if it lacked serum. These observations are consistent with the induction of cystine transport, particularly after oxidant stress, in many cell types $(40,41,16)$. Moreover, in K562 cells GSH recovered without significant change in GSSG-R activity. Finally, the rise in GSH was fully blocked by BSO, a relatively specific inhibitor of GSH synthesis. Thus, the data demonstrated that refeeding increased GSH by activating de novo biosynthesis.

The pattern of GSH regeneration suggested that biosynthesis was under homeostatic control. Several hours after the cells were refed, their GSH level began to increase rapidly, overshot, and then settled for the duration of the experimental period to a steady state that was maintained at about six times the baseline nadir in the systems without BCNU. The nitrosourea delayed, augmented, and prolonged the GSH response to the proliferative stimulus, so that the thiol level stabilized at 12 times above baseline or twice the control value. Thus, the leukemia line reproduced in vitro the elevation of GSH that developed in vivo in humans and other species after parenteral administration of $\operatorname{BCNU}(4,13,14)$.

BCNU, in contrast to its anti-GSSG-R effect, did not inhibit the enzymes of GSH synthesis (8). Moreover, BSO abolished the elevation of GSH found in nitrosourea-treated K562 cells. Thus, the thiol response found after addition of growth factors and treatment with BCNU was caused by increased GSH synthesis, as was the lesser increase in GSH that devel- 
oped in the no-drug systems. Because these experiments required that the cells be treated with both BCNU and BSO, we also examined whether these agents interfered with each other. While BCNU inactivated GSSG-R within minutes, BSO required several hours to block GSH synthesis and begin to deplete GSH. Moreover, we found that pretreatment with BSO diminished markedly the ability of BCNU to inhibit GSSG-R. The nitrosourea cannot block this enzyme or lipoamide dehydrogenase, a genetic homologue, as long as the active-site thiols remain oxidized in the absence of reduced coenzyme (42). Thus, it is likely that the BSO-induced loss of GSH decreased the cellular NADPH needed to keep GSSG-R in a nitrosoureasensitive state. This interpretation is corroborated by noting that the inhibition of GSSG-R by BCNU is also blunted in cells sampled when their GSH content was decreased by fasting rather than by BSO (Fig. 8). BCNU and BSO are widely used to interrupt recycling and synthesis of glutathione, respectively. When these agents are used together it may seem convenient, because BSO acts much more slowly than BCNU, to add the sulfoximine before the nitrosourea. Under those circumstances the hitherto unrecognized drug interaction between BSO and BCNU can lead to underestimation or misinterpretation of combined effects. The potential difficulty can be avoided if exposure to the nitrosourea precedes incubation with the sulfoximine in experiments designed to inhibit both GSH synthesis and GSSG-R.

The evidence discussed so far indicates that human leukemic cells exposed to growth factors greatly increase their GSH production before they start to synthesize DNA. This synthesis depends absolutely on the formation of pentoses and on their conversion into deoxyribose by ribonucleotide reductase $(30$, 43). The activity of this enzyme requires reduced glutaredoxin that must be maintained by GSH with concomitant oxidation to GSSG $(30,43)$. Thus, cells that prepare to proliferate need more thiol, as corroborated by our observations. GSSG-R provides not only GSH for glutaredoxin, but also plays a major role in activating glucose decarboxylation to produce pentoses by the HMS (11). Moreover, the shunt supported by GSSG-R is very efficient and has a large reserve capacity (8). Hence, as long as GSSG-R, G6PD, and 6PGD are functional, the rising demand for thiol as well as for pentoses in cells preparing to grow can be satisfied initially by increasing GSSG recycling with concomitant stimulation of the HMS. Nevertheless, we found that several hours after K562 cells were induced to proliferate they required so much GSH that GSSG recycling was supplemented by enhanced de novo thiol synthesis even when GSSG-R was intact in the systems without BCNU.

In the cells treated with BCNU, GSH synthesis increased even more after addition of growth factors than in the no-drug systems. While the thiol response was delayed for about $2 \mathrm{~h}$ without $\mathrm{BCNU}$, the lag was $\sim 3 \mathrm{~h}$ longer after exposure to the drug. Therefore, in drug-treated K562 cells, a period of $\sim 5 \mathrm{~h}$ separated the abrupt abolition of GSSG-R from the onset of enhanced GSH synthesis. The extra delay in the appearance of newly formed GSH after BCNU could be explained by the loss of cellular thiol recycling caused by the drug-induced GSSG-R deficiency. The subsequent prolonged overproduction of GSH found in the drug-treated systems was triggered most likely by increased utilization and heightened demand for the thiol. BCNU enhances GSH utilization by reacting with and removing the thiol and may also boost the demand for GSH to support glutaredoxin for ribonucleotide reductase $(23,30,31,42$, 44, 45).
The data just discussed have revealed that shortly after leukemia cells have been treated with $\mathrm{BCNU}$, while the drug generates moieties that can alkylate DNA, the cells enter a prolonged period when GSSG-R is lost, thiol utilization and requirements are both escalating, and GSH synthesis has not yet become upregulated. This constellation of events places the cells into a striking and previously unrecognized "window of vulnerability" for GSH dependent processes. Because the thiol is essential for several aspects of cell growth and GSSG-R activity is a key factor in regulating the decarboxylation of glucose and supporting ribonucleotide reductase, these processes are hampered by BCNU. Thus, as shown previously, the nitrosourea and hydroxyurea interact synergistically in blocking the proliferation of K562 cells ( 31 ). While hydroxyurea inactivates a functional tyrosyl group of ribonucleotide reductase, BCNU may not only interfere with the enzyme's supply of substrate and cofactor, but also with its catalytic center (46). Moreover, recent evidence indicates that GSH also plays a significant role in protecting the functional integrity of $\mathrm{O}^{6}$-alkylguanine-DNA alkyltransferase, an enzyme required to repair nitrosourea-induced DNA alkylation $(23,47)$. Hence, by destroying GSSG-R and raising GSH utilization and requirements before thiol synthesis is upregulated, BCNU could interfere with the decarboxylation of glucose into pentose, deoxyribose formation, DNA alkylation repair, and perhaps with other proliferation requirements.

The previous discussion has highlighted several ways in which the profound GSSG-R deficiency induced by BCNU interacted with other disturbances of thiol metabolism, in the presence of alkylating drug metabolites, to interfere with cellular events that precede proliferation. The data presented also show that while the antiproliferative effect of the nitrosourea was delayed, the drug-induced GSSG-R deficiency was not. This was further evidence that the acquired enzyme defect was not immediately and exclusively responsible for the drug's antiproliferative properties. In this light, how might one then interpret the fact that GSSG-R deficiency occurs so promptly, in vivo or in vitro, within therapeutic doses, and before the nitrosourea's other effects? The answer is to be found in all likelihood in that BCNU is a prodrug and its toxic, antitumor, and anti-GSSG-R effects are all mediated by drug breakdown products. The active site of GSSG-R is blocked through carbamoylation and alkylation by the chloroethylisocyanate derivative of $\mathrm{BCNU}$; this moiety is generated in parallel with other active breakdown products and inactivates GSSG-R as soon as it is formed $(4,42,48)$. Therefore, the acquired enzyme deficiency contributes not only indirectly to the drug's effects but must be viewed also as an early marker of prodrug breakdown and biological activation.

The multiple effects of BCNU on cellular glutathione metabolism discussed so far have all preceded the drug's impact on DNA synthesis. Moreover, we found that BCNU altered the production of both GSH and DNA only after hours of latency. It is tempting therefore to try to define more precisely how the nitrosourea-induced activation of GSH formation could be linked functionally to some of the drug's puzzling and even more delayed cytostatic and toxic effects. The problem is still unresolved. Furthermore, we do not yet understand why the timing of BCNU exposure influences K562 DNA synthesis so profoundly. A promising approach to clarify these issues is to focus further attention on the changes in GSH homeostasis that take place without or with BCNU within a few hours after the cells are stimulated to proliferate. The K562 leukemia sys- 
tem should continue to be a useful tool for such studies given that it reproduces many of the typical biological and biochemical features found in patients treated with nitrosoureas.

\section{Acknowledgments}

Supported in part by United Nations Development Programme-World Health Organization Special Programme for Research and Training in Tropical Diseases.

\section{References}

1. Frischer, H., P. E. Carson, J. E. Bowman, and K. H. Rieckmann. 1973. Visual test for erythrocytic glucose 6-phosphate dehydrogenase, 6-phosphogluconic dehydrogenase, and glutathione reductase deficiencies. J. Lab. Clin. Med. 81:613-24.

2. Frischer, H., J. E. Bowman, P. E. Carson, K. H. Rieckmann, W. D. Willerson, and E. M. Colwell. 1973. Erythrocytic glutathione reductase, glucose 6-phosphate dehydrogenase, and 6-phosphogluconic dehydrogenase deficiencies in populations of the United States, South Vietnam, Iran, and Ethiopia. J. Lab. Clin. Med. 81:603-612.

3. Frischer, H. 1977. Erythrocytic glutathione reductase deficiency in a hospital population in the United States. Am. J. Hematol. 2:327-334.

4. Frischer, H., and T. Ahmad. 1977. Severe generalized glutathione reductase deficiency after antitumor chemotherapy with BCNU [1,3-bis(2-chloroethyl)-1nitrosourea]. J. Lab. Clin. Med. 89:1080-1091.

5. Nathan, C. F., B. A. Arrick, H. W. Murray, N. M. DeSantis, and Z. A. Cohn. 1980. Tumor cell antioxidant defenses. Inhibition of the glutathione redox cycle enhances macrophage-mediated cytolysis. J. Exp. Med. 153:766-782.

6. McKenna, R., T. Ahmad, C. H. Tsao, and H. Frischer. 1983. Glutathione reductase deficiency and platelet dysfunction induced by 1,3-bis(2-chloroethyl)1-nitrosourea. J. Lab. Clin. Med. 102:102-115.

7. Arrick, B. A., and C. F. Nathan. 1984. Glutathione metabolism as a determinant of therapeutic efficacy: a review. Cancer Res. 44:4224-4232.

8. Frischer, H., and T. Ahmad. 1987. Consequences of erythrocytic glutathione reductase deficiency. J. Lab. Clin. Med. 109:583-588.

9. Reed, D. J. 1990. Glutathione: toxicological implications. Annu. Rev. Pharmacol. Toxicol. 30:603-631.

10. Sies, H. 1991. Oxidative stress: from basic research to clinical application. Am. J. Med. 91 (Suppl. 3C):31-38.

11. Hohl, R. J., E. J. Kennedy, and H. Frischer. 1991. Defenses against oxidation in human erythrocytes: role of glutathione reductase in the activation of glucose decarboxylation by hemolytic drugs. J. Lab. Clin. Med. 117:325-331.

12. Weiss, R. B., D. S. Poster, and J. S. Penta. 1981. The nitrosoureas and pulmonary toxicity. Cancer Treat. Rev. 8:111-125.

13. Smith, A. C., and M. R. Boyd. 1984. Preferential effects of 1,3-bis(2chloroethyl)-1-nitrosourea (BCNU) on pulmonary glutathione reductase and glutathione/glutathione disulfide ratios: possible implications for lung toxicity. J. Pharmacol. Exp. Ther. 229:658-663.

14. Jenkinson, S. G., J. M. Jordan, and R. A. Lawrence. 1988. BCNU-induced protection from hyperbaric hyperoxia: role of glutathione metabolism. $J$. Appl. Physiol. 65:2531-2536.

15. O'Driscoll, B. R., P. S. Hasleton, P. M. Taylor, L. W. Poulter, H. R Gattameneni, and A. A. Woodcock. 1990. Active lung fibrosis up to 17 years after chemotherapy with carmustine (BCNU) in childhood. N. Engl. J. Med. 323:378382.

16. Deneke, S. M., R. A. Lawrence, and S. G. Jenkinson. 1992. Endothelial cell cystine uptake and glutathione increase with $N, N$-bis(2-chloroethyl)- $N$-nitrosourea exposure. Am. J. Physiol. 262:301-304.

17. Erickson, L. C., G. Laurent, N. A. Sharkey, and K. W. Kohn. 1980. DNA crosslinking and monoadduct repair in nitrosourea-treated human tumour cells. Nature (Lond.). 288:727-729.

18. Tong, W. P., M. C. Kirk, and D. B. Ludlum. 1982. Formation of the crosslink 1-[N3-deoxycytidyl],2-[N1-deoxyguanosinyl]ethane in DNA treated with $N, N$-bis(chloroethyl)- $N$-nitrosourea. Cancer Res. 42:3102-3105.

19. Brent, T. P. 1985. Isolation and purification of $O^{6}$-alkylguanine-DNA alkyltransferase from human leukemic cells: prevention of chloroethylnitrosourea-induced cross-links by purified enzyme. Pharmacol. \& Ther. 31:121-140.

20. Yarosh, D. B., S. Hurst-Calderone, M. A. Babich, and R. S. Day III. 1986. Inactivation of $\mathrm{O}^{6}$-methylguanine-DNA methyltransferase and sensitization of human tumour cells to killing by chloroethylnitrosourea by $\mathrm{O}^{6}$-methylguanine as a free base. Cancer Res. 46:1663-1668.

21. Gerson, S. L., J. E. Trey, and K. Miller. 1988. Potentiation of nitrosourea cytotoxicity in human leukemic cells by inactivation of $\mathrm{O}^{6}$-alkylguanine-DNA alkyltransferase. Cancer Res. 48:1521-1527.

22. D'Incalci, M. D., L. Citti, P. Taverna, and C. V. Catapano. 1988. Importance of the DNA repair enzyme $\mathrm{O}^{6}$-alkylguanine alkyltransferase in cancer chemotherapy. Cancer Treat. Rev. 279-292.

23. Ali-Osman, F., J. Caughlan, and G. S. Gray. 1989. Decreased DNA inter- strand cross-linking and cytotoxicity induced in human brain tumour cells by 1,3-bis(2-chloroethyl)-1-nitrosourea after in vitro reaction with glutathione. Cancer Res. 49:5954-5948.

24. Pegg, A. E. 1990. Mammalian $\mathrm{O}^{6}$-alkylguanine-DNA alkyltransferase: regulation and importance in response to alkylating carcinogenic and therapeutic agents. Cancer Res. 50:6119-6129.

25. Dumenco, L. L., E. Allay, K. Norton, and S. L. Gerson. 1993. The prevention of thymic lymphomas in transgenic mice by human $\mathrm{O}^{6}$-alkylguanine-DNA alkyltransferase. Science (Wash. DC). 259:219-222.

26. Meister, A., and M. E. Anderson. 1983. Glutathione. Annu. Rev. Biochem 52:711-760.

27. Meister, A. 1991. Glutathione deficiency produced by inhibition of its synthesis, and its reversal; applications in research and therapy. Pharmacol. \& Ther. 51:155-194.

28. Mannervik, B. 1987. The enzymes of glutathione metabolism: an overview. Biochem. Soc. Trans. 15:717-718.

29. Suthanthiran, M., M. E. Anderson, V. K. Sharma, and A. Meister. 1990. Glutathione regulates activation-dependent DNA synthesis in highly purified normal human $\mathrm{T}$ lymphocytes stimulated via the $\mathrm{CD} 2$ and $\mathrm{CD} 3$ antigens. Proc. Natl. Acad. Sci. USA 87:3343-3347.

30. Holmgren, A. 1979. Glutathione dependent synthesis of deoxyribonucleotides. J. Biol. Chem. 254:3664-3671.

31. Frischer, H., M. Sivarajan, R. Mellovitz, and T. Ahmad. 1985. Synergistic inhibition of DNA synthesis in the human K562 tumor line by 1,3-bis-(2-chloroethyl)-1-nitrosourea, hydroxyurea, and 2'-deoxyadenosine with 2'-deoxycoformycin. In Recent Advances in Chemotherapy. J. Ishigami, editor. University of Tokyo Press, Tokyo. 387-388.

32. Frischer, H., T. Ahmad, M. V. Nora, P. E. Carson, M. Sivarajan, R. Mellovitz, L. Ptak, G. W. Parkhurst, H. S. Chow, and H. Kaizer. 1987. Biotransformation of primaquine in vitro with human $\mathrm{K} 562$ and bone marrow cells. $J$. Lab. Clin. Med. 109:414-421.

33. Frischer, H., R. Mellovitz, T. Ahmad, and M. V. Nora. 1991. The conversion of primaquine into primaquine-aldehyde, primaquine-alcohol, and carboxyprimaquine, a major plasma metabolite. J. Lab. Clin. Med. 117:468-476.

34. Griffith, O. W., and A. Meister. 1979. Potent and specific inhibition of glutathione synthesis by buthionine sulfoximine (S-butyl Homocysteine Sulfoximine). J. Biol. Chem. 254:7558-7560.

35. Tietze, F. 1969. Enzymic method for quantitative determination of nanogram amounts of total and oxidized glutathione. Anal. Biochem. 27:502-522.

36. Lowry, O. H., N. J. Rosebrough, A. L. Farr, and R. J. Randall. 1951. Protein measurement with the Folin phenol reagent. J. Biol. Chem. 193:265275.

37. Holley, R. W., and J. Kiernan. 1974. Control of the initiation of DNA synthesis in 3T3 cells: serum factors. Proc. Natl. Acad. Sci. USA 71:2908-2911.

38. DeVita, V. T., C. Denham, J. D. Davidson, and V. T. Oliverio. 1967. The physiological disposition of the carcinostatic 1,3-bis(2-chloroethyl)-1-nitrosourea (BCNU) in man and animals. Clin. Pharmacol. \& Ther. 8:566-577.

39. Levin, V. A. 1981. Clinical pharmacology of the nitrosoureas. In Nitrosoureas Current Status and New Developments. A. W. Prestayko, S. T. Crooke, L. H. Baker, S. K. Carter, and P. S. Schein, editors. Academic Press, New York. 171-180.

40. Bannai, S. 1984. Induction of cystine and glutamate transport activity in human fibroblasts by diethylmaleate and other electrophilic agents. J. Biol. Chem. 259:2435-2440.

41. Bannai, S., and N. Tateishi. 1986. Role of membrane transport in metabolism and function of glutathione in mammals. J. Membr. Biol. 89:1-8.

42. Ahmad, T., and H. Frischer. 1985. Active site-specific inhibition by 1,3bis(2-chloroethyl)-1-nitrosourea of two genetically homologous flavoenzymes: glutathione reductase and lipoamide dehydrogenase. J. Lab. Clin. Med. 105:464-471.

43. Holmgren, A. 1981. Regulation of ribonucleotide reductase. Curr. Top. Cell. Regul. 19:47-76.

44. Colvin, M., and B. A. Chabner. 1990. Alkylating agents. In Cancer Chemotherapy: Principles and Practice. B. A. Chabner and J. M. Collins, editors. J. B. Lippincott Co., Philadelphia. 276-313.

45. Chresta, C. M., T. R. Crook, and R. L. Souhami. 1990. Depletion of cellular glutathione by $N, N^{\prime}$-bis(trans-4-hydrocyclohexyl)- $N^{\prime}$-nitrosourea as a determinant of sensitivity of K562 human leukemia cells to 4-hydroperoxycyclophosphamide. Cancer Res. 50:4067-4071.

46. Schallreuter, K. U., F. K. Gleason, and J. M. Wood. 1990: The mechanism of action of the nitrosourea anti-tumor drugs on thioredoxin reductase, glutathione reductase, and ribonucleotide reductase. Biochim. Biophys. Acta. 1054:14-20.

47. Lee, S. M., D. Crowther, J. H. Scarffe, M. Dougal, R. H. Elder, J. A. Rafferty, and G. P. Margison. 1992. Cyclophosphamide decreases $\mathrm{O}^{6}$-alkylguanine-DNA alkyltransferase in peripheral lymphocytes of patients undergoing bone marrow transplantation. Br. J. Cancer 66:331-336.

48. Montgomery, J. A. 1981. The Development of the nitrosoureas: a study in congener synthesis. In Nitrosoureas Current Status and New Developments. A. W. Prestayko, S. T. Crooke, L. H. Baker, S. K. Carter, and P. S. Schein, editors. Academic Press, New York. 3-8. 